\title{
Оцінка доцільності використання одноетапної стратегії лікування холедохолітіазу та холецистолітіазу шляхом виконання симультанних лапароскопічних втручань із двохетапною стратегією
}

\begin{abstract}
Мета роботи: вивчення ускладнень, пов’язаних із одноетапною стратегією лікування холедохолітіазу та холецистолітіазу, що передбачає виконання симультанної холецистектомії та холедохолітотомії з інтраопераційною холангіографією, використовуючи власний розроблений метод встановлення лапароскопічних портів, та оцінка доцільності використання кожного із методів. Матеріали і методи. У період із 2015 до 2019 р. проліковано 118 пацієнтів із поєднанням холедохолітіазу та холецистолітіазу. Усі пацієнти проходили операційне лікування із використанням розробленої техніки виконання симультанних операцій. Порівняння тривалості лікування та профілю безпеки розробленого методу проводили із таким для двохетапного методу із використанням ендоскопічної ретроградної холангіопанкреатографії (ЕРХПГ). Контрольними точками досліджень були тривалість перебування у стаціонарі та частота ускладнень. Дані про згадані показники отримано із публікацій наших колег.

Результати досліджень та їх обговорення. Тривалість лікування у дослідній групі склала 4 ліжко-дні, що менше від тривалості лікування у дослідах наших колег (не менше 6 днів). Рівень ускладнень при використанні одноетапного методу із власною технікою склав 0,85 \%, що суттєво менше від сумарного рівня місцевих і загальних ускладнень, характерних для ЕРХПГ (6,85 \%). Якщо повторна ( 12-23 \%), то рівень ускладнень зростає до 19,35 \%, що, на нашу думку, є неприйнятим ризиком. Також для одноетапного методу нехарактерними ускладненнями є гострий панкреатит, холангіт, перфорація кишечника та септичні стани, включно пов'язані із резистентною мікрофлорою. Використання неінвазивного методу (МРХПГ) для діагностики холедохолітіазу є пріоритетним над інвазивним і небезпечним ЕРХПГ.
\end{abstract}

Ключові слова: ендоскопічна ретроградна холангіопанкреатографія; лапароскопія; симультанні операції; жовчнокам’яна хвороба; МРХПГ.

Постановка проблеми і аналіз останніх досліджень та публікацій. На сьогодні захворюваність дорослого населення Європи на жовчнокам'яну хворобу (ЖКХ) складає до 30 \% від усіх хірургічних патологій [1]. Холедохолітіаз є ускладненням ЖКХ у 20 \% випадків, а гострі форми холецистолітіазу часто складно відрізнити від холелітіазу через жовтяницю та набряк гепато-дуоденальної зв'язки [2]. Розвиток технологій дає можливість використовувати магнітнорезонансну холангіопанкреатографію (МРХПГ) для диференціальної діагностики без використання інвазивних і ризикованих методів високою точністю [3]. Також є дані, що вказують на високу ефективність проведення симультанної антеградної інтраопераційної холангіографії під час холецистектомії для виключення чи верифікації холедохолітіазу [4]. При підтвердженні холедохолітіазу найбільш адекватною стратегією є виконання холедохолітотомії. Відповідно цей факт ставить додаткові вимоги до ергономіки операції, щоб забезпечити оптимальну візуалізацію та дали можливісь виконати усі операційні маневри симультанно і лапароскопічно. У роботі проведено оцінку використання техніки введення лапароскопічних портів для симультанного виконання лапа- роскопічних холецистектомії та холедохолітотомії з інтраопераційною антеградною холангіографією; проаналізовано методи лікування ЖКХ із холедохолітіазом та наведено дані щодо лікування напрацьованих в умовах відділення інвазивних методів діагностики та лікування Волинської обласної клінічної лікарні (ВІМДЛ ВОКЛ). Проведено порівняння ефективності, безпеки, швидкості та етапності, а також доцільність одноетапного та двохетапного підходів у лікуванні ЖКХ.

Мета роботи: оцінка доцільності використання одно- та двохетапного методів лікування поєднання холедохолітіазу та холецистолітіазу через аналіз та порівняння рівня ускладнень процедур та операцій пов'язаних із лікувально-діагностичним процесом, регламентованим у кожному з методів.

Матеріали і методи. Для аналізу використано статистику з незалежних перевірених наукових джерел щодо безпеки, ускладнень, смертності, ефективності, а також доцільності виконання ЕРХПГ. Для порівняння використано статистику, напрацьовану в умовах ВІМДЛ ВОКЛ, а саме 118 випадків поєднання калькульозного холециститу 3 холедохолітіазом та механічною жовтяницею, яким виконували лапароскопічну холедохоліто- 
томію (ХЛТ), інтраопераційну холангіографію (ІоХГ), лапароскопічну холецистектомію (ЛХЕ). Структура пацієнтів проаналізована за віком, статтю (табл. 1), а виконані операції за об’ємом самого втручання у межах однієї операційної зони (табл. 2).

Таблиця 1. Розподіл хворих за віком і статтю

\begin{tabular}{|c|c|c|c|c|c|c|c|c|}
\hline \multirow{3}{*}{$\begin{array}{c}\text { Назви операційних } \\
\text { втручань }\end{array}$} & \multicolumn{8}{|c|}{ Вік хворих, роки } \\
\hline & \multicolumn{2}{|c|}{$25-44$} & \multicolumn{2}{|c|}{$45-60$} & \multicolumn{2}{|c|}{$60-75$} & \multicolumn{2}{|c|}{$75-90$} \\
\hline & чоловіки & жінки & чоловіки & жінки & чоловіки & жінки & чоловіки & жінки \\
\hline ЛХЕ+холедохолітотомія & 2 & 14 & 9 & 18 & 15 & 31 & 12 & 17 \\
\hline
\end{tabular}

Таблиця 2. Розподіл хворих за об'ємом операційного втручання

\begin{tabular}{||c|c|c|c||}
\hline \multirow{2}{*}{$\begin{array}{c}\text { Характер операційних } \\
\text { втручань }\end{array}$} & \multicolumn{3}{|c||}{ Об’єм операційних втручань } \\
\cline { 2 - 4 } & низький & середній & великий \\
\hline ЛХЕ+холедохолітотомія & 0 & 107 & 11 \\
\hline
\end{tabular}

Результати досліджень та їх обговорення. Одноетапний метод - лікування шляхом операції, при якій виконується лапароскопічно холедохолітотомія, інтраопераційна холангіографія, симультанно лапароскопічна холецистектомія, з попередньою діагностикою і МРХПГ. Тривалість такого лікування, включно 1 день на діагностику, складає 4 дні, після чого хворий не потребує перебування в стаціонарі.

Двохетапний метод - лікування через виконання ЕРХПГ, із подальшим виконанням холецистектомії. Тривалість лікування, включно 1 день на діагностику, 2 дні після виконання ЕРХПГ, холецистектомію, при умові відсутності ускладнень після ЕРХПГ, складає не менше 6 днів.

ЕРХПГ є достатньо небезпечною хірургічною операцією з вузьким колом показань, а саме:

1. Діагностичні - пухлина підшлункової залози, хронічний панкреатит.

2. Лікувальні - стриктуротомія, папілосфінктеротомія, ендоскопічна екстракція конкременту, введення стентів холедоха.

Після виконання ЕРХПГ для завершення лікування ЖКХ потрібно виконувати холецистектомію, яка також спричиняє ускладнення, пов'язані як з операцією, так і з госпіталізацією та перебуванням у стаціонарі. За різними літературними даними, виконання лише ЕРХПГ супроводжується високим ризиком ускладнень, а саме:

- гострий панкреатит до 5 \% (якщо ЕРХПГ повторна, то ризик зростає до 17,5 \%) [1-4];
- перфорація 0.60 \% (CI 0.48-0.72 \%) (якщо низхідна ДПК ретроперитонеально $0.94 \%$, CI 1.22-1.4\%) [5, 6];

- кровотеча 1.34 \% (CI 1.16-1.52 \%) [8, 9];

- антибіотикорезистентні інфекції 1,44 \% (СI $1.26-1.62 \%)[7] ;$

- холангіт $0.98 \%$ (95 \% CI 0.35-2.69) [8];

- дуоденіт 0.54 \% (95 \% СI 0.33-0.91) [8];

- септицемія $0.35 \%$ (95 \% CI 0.11-1.11) [8, 9];

- бактеріємія $0.50 \%$ (95\% CI 0.33-0.78) [8, 9].

Загалом рівень ускладнень - 6.85 \% (CI 6.46$7.24 \%$ ) смертність - $0.33 \%$ (СI 0.24-0.42 \%) [10].

При використанні складеного алгоритму лікування холедохолітіазу та калькульозного холециститу одноетапним шляхом із попереднім виконанням, окрім рутинного дослідження, магнітно-резонансного холангіографічного обстеження, виконується лапароскопічна холедохолітотомія, для топічного визначення конкрементів та контролю - лапароскопічна інтраопераційна холангіографія, завершальним етапом $є$ лапароскопічна холецистектомія. МРХПГ $є$ безпечним та ефективним методом діагностики ЖКХ [11, 12], оскільки не $є$ інвазивним, а також забезпечує найвищий можливий рівень візуалізації жовчних шляхів та їх патологічних змін. Можливості візуалізації жовчного дерева за допомогою магнітно-резонансної технології продемонстровані на рисунках 1 та 2.

Виконання лапароскопічної холедохолітотомії має суттєві переваги перед ЕРХПГ, адже не 


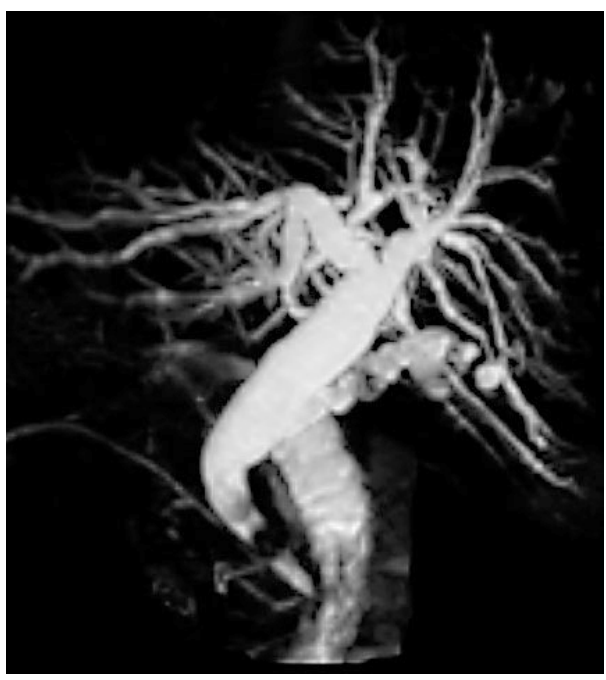

Рис. 1. 3D моделювання.

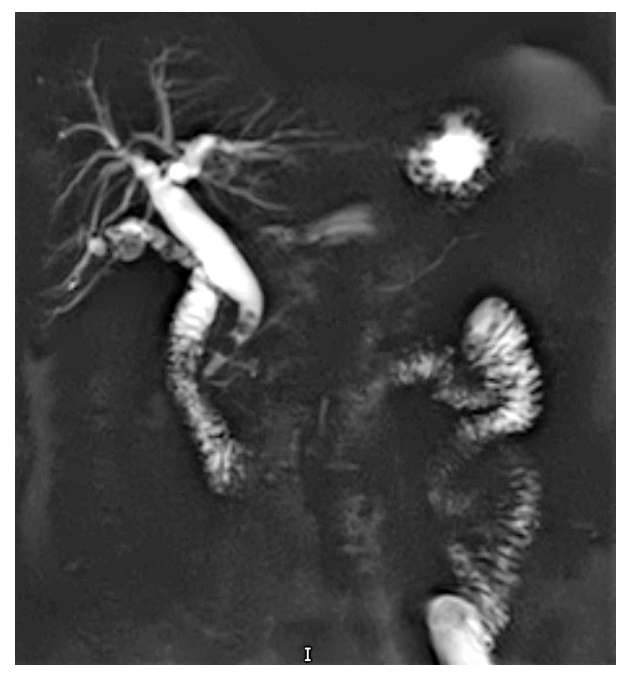

Рис. 2. 2D проекція.

руйнує папіло-сфінктерний апарат, не спричиняє ретроградного току жовчі в холедосі чи секрету у панкреатичній протоці, що унеможливлює панкреатит, а також затікання кишкового вмісту з подальшим холангітом. Також лапароскопічна ХЛТ виконується разом за ІоХГ та холецистектомією, що не потребує додаткової інвазії, не збільшує ризики інфікування ран, а також не призводить до зростання інтраопераційних чи постопераційних ускладнень порівняно з виконанням лише ХЛТ.

Можливості візуалізації під час виконання лапароскопічної холедохолітотомії з симультанними холецистектомією та антеградною інтраопераційною холангіографією продемонстровано на рисунках 3 і 4.

Також кількість госпіталізацій та часу перебування у стаціонарі не зростає, що й не підвищує пов’язані з цим ризики. Пошкодження кишечни-
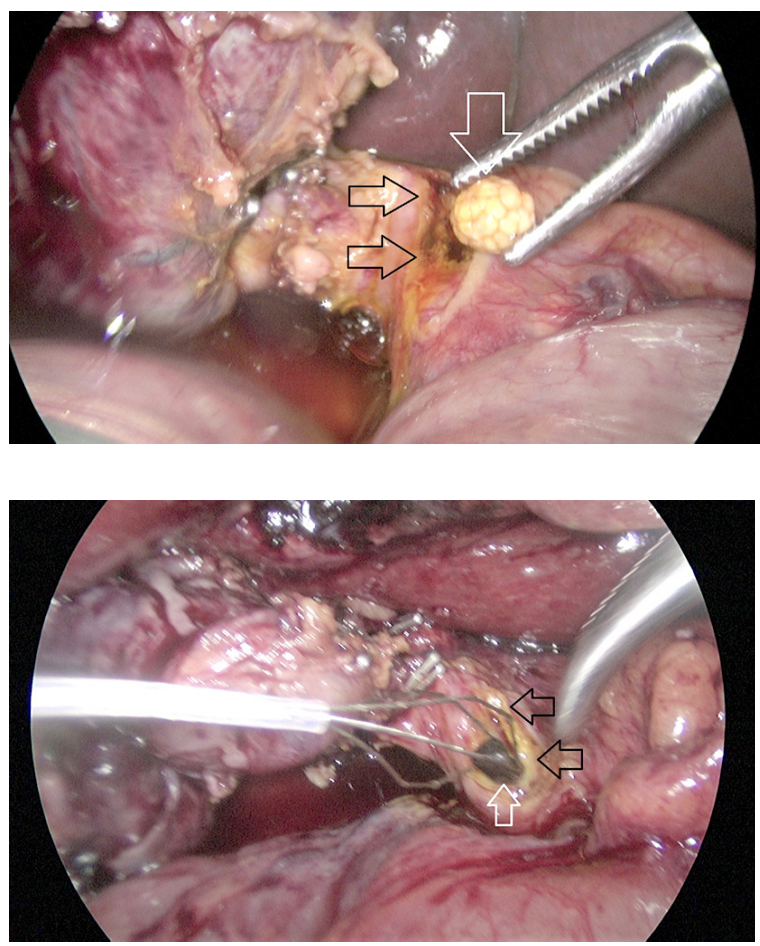

Рис. 3. Інтраопераційна візуалізація (Karl Storz ${ }^{\mathrm{TM}}$ Hopkins II® $30^{\circ}$ ). Жовчні конкременти (холестериновий та пігментний) вказані білою стрілкою, холедохотомний отвір вказаний чорною стрілкою.

ка і спричинені цим кровотечі теж нехарактерні через вищий рівень контролю інструмента та візуалізацію.

На етапі операційного лікування ми використовували косу оптику $30^{\circ}$, для встановлення портів, місце введення та співвідношення між ними ми розраховували за формою, розробленою у ВІМДЛ ВОКЛ.

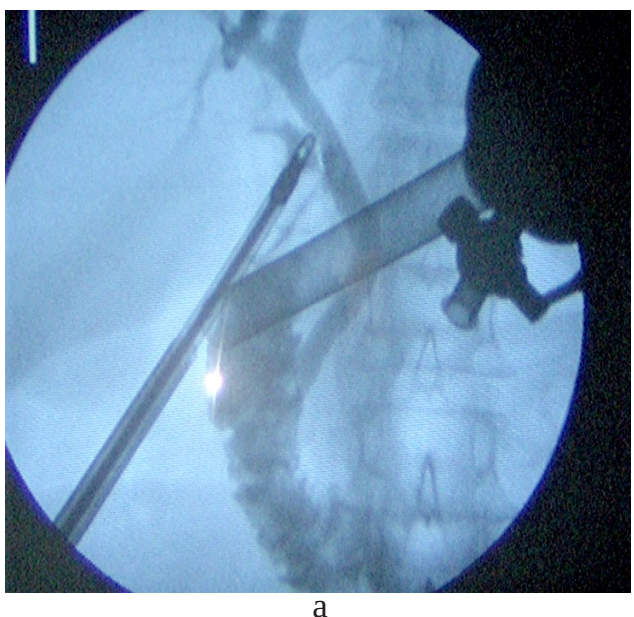

Рис. 4. Інтраопераційна антеградна холангіографія йодовмісним контрастом (Intermedical ${ }^{\mathrm{TM}}$ Radius $\left.{ }^{\circledR}\right)$ : a нормальна ІоХГ; 


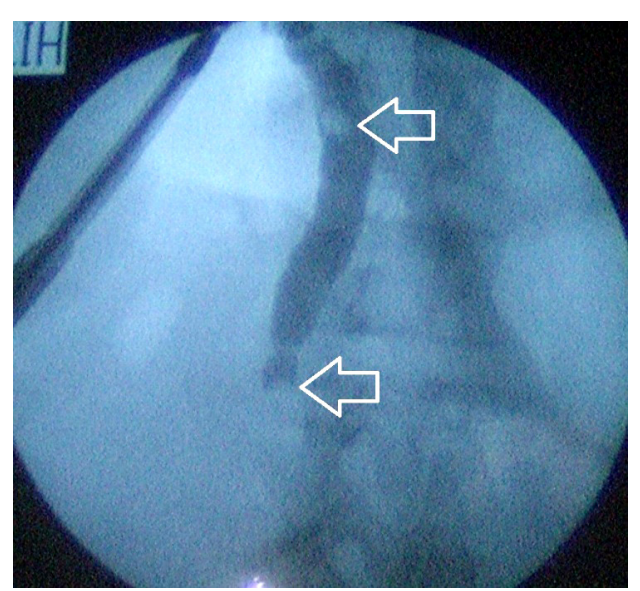

б

Рис. 4 (продовження). Інтраопераційна антеградна холангіографія йодовмісним контрастом (Intermedical ${ }^{\mathrm{TM}}$ Radius $\left.{ }^{\circledR}\right)$ : 6 - ІоХГ холедохолітіазу, де білими стрілками вказано конкременти.

Ендовідеопорт вводиться над пупком із відстанню в $1 \frac{2}{2}$ довжини лапароскопа до зони хірургічної роботи, кут між маніпуляторами від 60 до 90 градусів та місцями введення, вказаними на рисунку 5. Це забезпечує максимальну ергономіку операції.

Висновки. 1. Використання магнітно-резонансної холангіопанкреатографії в комбінації із інтраопераційною антеградною холангіографією дає можливість отримати максимально достовірні дані щодо наявності чи відсутності холедохолітіазу, без ризиків панкреатитів, перфорацій по-

\section{СПИСОК ЛІТЕРАТУРИ}

1. Prophylaxis of post-ERCP pancreatitis: European Society of Gastrointestinal Endoscopy (ESGE) Guideline - updated June 2014 / J. M. Dumonceau, A. Andriulli, B. J. Elmunzer [et al.] // Endoscopy. - 2014. - Vol. 46. - P. 799-815.

2. GallRiks. Annual report. - 2016. - URL : http://www.ucr. uu.se/gallriks/fou/arsrapporter [accessed 31 May 2018].

3. Freeman M. L. Post-ERCP pancreatitis: patient and technique-related risk factors / M. L. Freeman // JOP. - 2002. Vol. 3. - P. 169-176.

4. Risk factors for post-ERCP pancreatitis: a systematic review of clinical trials with a large sample size in the past 10 years / J. J. Chen, X. M. Wang, X. Q. Liu [et al.] // Eur. J. Med. Res. 2014. - Vol. 15. - P. 19-26.

5. Incidence rates of post-ERCP complications: a systematic survey of prospective studies / A. Andriulli, S. Loperfido, G. Napolitano [et al.] // Am. J. Gastroenterol. - 2007. - Vol. 102 (8). P. 1781-1788.

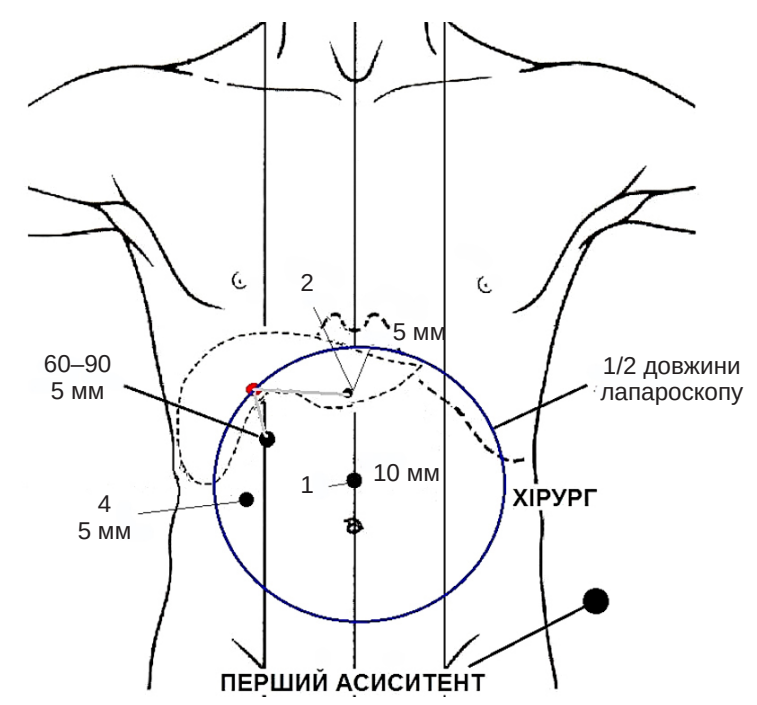

Рис. 5. Співвідношення і місце введення портів.

рожнистих органів, інфекцій та інших ускладнень пов'язаних з ЕРХПГ.

2. Використання розробленої на базі ВІМДЛ ВОКЛ техніки симультанних операцій дає можливість виконувати одномоментне лікування холецистолітіазу та холедохолітіазу без шкоди для ергономічних показників.

3. Неінвазивна МРХПГ у поєднанні із симультанними лапароскопічними операціями дає можливість надавати медичну допомогу пацієнтам із мінімальними затратами часу, термінами шпиталізації, без неприємних та больових відчуттів пов’язаних з ЕРХПГ, а також у повному обсязі без потреби повторної шпиталізації.

6. Cotton, Peter B. (2013-05-31). HYPERLINK "http://www. ddc.musc.edu/public/testsProcedures/procedures/ERCP.cfm" “ERCP (Endoscopic Retrograde Cholangio-Pancreatography)”. Medical University of South Carolina (MUSC) Digestive Disease Center. Retrieved 2013-06-09.

7. Sharon Begley; Toni Clarke (20 February 2015). HYPERLINK "https://www.reuters.com/article/2015/02/20/us-usa-ucladevices-idUSKBNOLO02Q20150220” “FDA knew devices spread fatal 'superbug' but does not order fix”. Reuters. Retrieved 20 February 2015.

8. URL : https://www.cochranelibrary.com/cdsr/doi/10.1002/ 14651858.CD007345.pub2/full

9. Brand M. Antibiotic prophylaxis for patients undergoing elective endoscopic retrograde cholangiopancreatography / M. Brand, D. Bizos, P. O’Farrell Jr // Cochr. Database Syst. Rev. - 2010. Vol. 10. - CD007345. HYPERLINK "https://en.wikipedia.org/ wiki/Digital_object_identifier” DOI: HYPERLINK “https://doi. 
org/10.1002\%2F14651858.CD007345.pub2” 10.1002/14651858. CD007345.pub2. HYPERLINK "https://en.wikipedia.org/wiki/PubMed_Identifier” PMID HYPERLINK “https://www.ncbi. nlm.nih.gov/pubmed/20927758” 20927758.
10. https://www.nature.com/articles/ajg2007345.

11. https://journals.sagepub.com/doi/ pdf/10.1177/145749690509400108.

12. http://www.mif-ua.com/archive/article/35421

\title{
REFERENCES
}

1. Dumonceau, J.M., Andriulli, A., Elmunzer, B.J., Mariani, A., Meister, T., Deviere, J., ..., \& Kapral, C. (2014). European Society of Gastrointestinal Endoscopy. Prophylaxis of post-ERCP pancreatitis: European Society of Gastrointestinal Endoscopy (ESGE) Guideline. Updated June 2014. Endoscopy, 46, 799-815. 2. GallRiks. Annual report 2016. Retrieved from: http: //www. ucr.uu.se/gallriks/fou/arsrapporter.

3. Freeman, M.L. (2002). Post-ERCP pancreatitis: patient and technique-related risk factors. JOP, 3, 169-176.

4. Chen, J.J., Wang, X.M., Liu, X.Q., Li, W., Dong, M., Suo, Z.W., ..., \& Li, Y. (2014). Risk factors for post-ERCP pancreatitis: a systematic review of clinical trials with a large sample size in the past 10 years. Eur. J. Med. Res., 15, 19-26. 5. Andriulli, A., Loperfido, S., Napolitano, G., Niro, G. Valvano, M.R., Spirito, F., ..., \& Forlano, R. (2007). Incidence rates of post-ERCP complications: a systematic survey of prospective studies. Am. J. Gastroenterol., 102 (8), 1781-1788.
6. Cotton, P.B. (2013). ERCP (Endoscopic Retrograde Cholangio-Pancreatography). Medical University of South Carolina (MUSC) Digestive Disease Center. Retrieved 2013-0609.

7. Begley, S., Clarke, T. (2015). FDA knew devices spread fatal superbug but doesn't order fix. Reuters. Retrieved 20 February 2015.

8. https://www.cochranelibrary.com/cdsr/ doi/10.1002/14651858.CD007345.pub2/full

9. Brand, M, Bizos, D, \& O’Farrell, P., Jr (2010). Antibiotic prophylaxis for patients undergoing elective endoscopic retrograde cholangiopancreatography. Cochr. Database Syst. Rev., 10, CD007345. DOI:10.1002/14651858.CD007345.

10. https://www.nature.com/articles/ajg2007345.

11. https://journals.sagepub.com/doi/ pdf/10.1177/145749690509400108.

12. http://www.mif-ua.com/archive/article/35421.

\section{M. HALEI ${ }^{1}$, I. YA. DZIUBANOVSKY ${ }^{2}$, I. P. MARCHUK ${ }^{1}$}

Volynian Regional Clinical Hospital ${ }^{1}$

I. Horbachevsky Ternopil National Medical University²

\section{EVALUATION OF THE FEASIBILITY OF USING A ONE-STAGE STRATEGY FOR THE TREATMENT OF CHOLEDOCHOLITHIASIS AND CHOLECYSTOLITHIASIS BY PERFORMING SIMULTANEOUS LAPAROSCOPIC INTERVENTIONS WITH A TWO-STAGE STRATEGY}

\begin{abstract}
The aim of the work: to study the complications associated with a one-stage strategy for the treatment of choledocholithiasis and cholecystolithiasis, which involves simultaneous cholecystectomy and choledocholithotomy with intraoperative cholangiography using our own developed method of setting laparoscopic ports. Evaluation of the feasibility of using each of the methods.

Materials and Methods. In the period from 2015 to 2019, 118 patients with a combination of choledocholithiasis and cholecystolithiasis were treated. All patients underwent surgical treatment using the developed technique of simultaneous operations. The comparison of treatment duration and safety profile of the developed method was performed with that for the two-stage method using endoscopic retrograde cholangiopancreatography. The control points of the studies were the length of hospital stay and the frequency of complications. Data on these indicators are obtained from the publications of our colleagues.

Results and Discussion. The duration of treatment in the study group was 4 bed-days, which is less than the duration of treatment in the experiments of our colleagues (at least 6 days). The level of complications when using the one-stage method with own technique was $0.85 \%$, which is significantly less than the total level of local and general complications typical for ERCP (6.85 \%). If ERCP is recurrent (12-23\%), the level of complications increases to $19.35 \%$, which in our opinion is an unacceptable risk. Acute pancreatitis, cholangitis, intestinal perforation, and septic conditions, including those associated with resistant microflora, are also uncommon complications for one-stage method. The use of a non-invasive method (MRCP) for the diagnosis of choledocholithiasis is a priority over invasive and dangerous ERCP.
\end{abstract}

Key words: ERCP; laparoscopy; simultaneous operations; gallstone disease; MRCP. 
Н. М. ГАЛЕЙ ${ }^{1}$, И. Я. ДЗЮБАНОВСКИЙ ${ }^{2}$, И. П. МАРЧУК ${ }^{1}$

КП “Волынская областная клиническая больница"1

Тернопольский национальный медицинский университет имени И. Я. Горбачевского МОз Украины²

\section{ОЦЕНКА ЦЕЛЕСООБРАЗНОСТИ ИСПОЛЬЗОВАНИЯ ОДНОЭТАПНОЙ СТРАТЕГИИ ЛЕЧЕНИЯ ХО.ЛЕДОХОЛИТИАЗА И ХО.ЛЕЦИСТО.ЛИТИАЗА ПУТЕМ ВЫПОЛНЕНИЯ СИМУЛЬТАННЫХ ЛАПАРОСКОПИЧЕСКИХ ВМЕШАТЕЛЬСТВ С ДВУХЭТАПНОЙ СТРАТЕГИЕЙ}

Цель работы: исследование осложнений, связанных с одноэтапной стратегией лечения холедохолитиаза и холецистолитиаза, что предполагает выполнение симультанной холецистэктомии и холедохолитотомии с интраоперационной холангиографией, используя собственную разработанную технику установки лапароскопических портов, и оценка целесообразности использования каждого из методов.

Материалы и методы. В период с 2015 по 2019 г. пролечено 118 пациентов с сочетанием холедохолитиаза и холецистолитиаза. Все пациенты проходили операционное лечение с использованием разработанной техники выполнения симультанных операций. Сравнение продолжительности лечения и профиля безопасности разработанного метода проводилось с таковым для двухэтапного метода с использованием эндоскопической ретроградной холангиопанкреатографии (ЭРХПГ). Контрольными точками исследования были длительность пребывания в стационаре и частота осложнений. Данные об упомянутых показателях получены из публикаций наших коллег.

Результаты исследований и их обсуждение. Продолжительность лечения в исследуемой группе составила 4 койко-дня, что меньше, чем продолжительность лечения в исследованиях наших коллег (не менее 6 дней). Уровень осложнений при использовании одноэтапного метода с собственной техникой составил 0,85 \%, что существенно меньше суммарного уровня местных и общих осложнений, характерных для ЭРХПГ (6,85 \%). Если ЭРХПГ повторная (12-23 \%), то уровень осложнений возрастает до 19,35 \%, что, по нашему мнению, является неприемлемым риском. Также для одноэтапного метода нехарактерными осложнениями являются острый панкреатит, холангит, перфорация кишечника и септические состояния, включая связанные с резистентной микрофлорой. Использование неинвазивного метода (МРХПГ) для диагностики холедохолитиаза является приоритетным над инвазивным и опасным ЭРХПГ.

Ключевые слова: эндоскопическая ретроградная холангиопанкреатография; лапароскопия; симультанные операции; желчнокаменная болезнь; МРХПГ. 